BOOK AND MEDIA REVIEW

\section{Female Genital Mutilation (FGM): A Deadly Degrading Painful Practice}

Emmanuel Ebah. Glasgow, UK: Divine Spark Publications, 2015. Kindle Edition. File size: 824 KB. Pages: 50 (print length). Simultaneous device usage: unlimited. Price: $£ 2.62$ (free on kindleunlimited)

Readers of this journal will be familiar with the short- and long-term outcomes of female genital mutilation (FGM), both physical and emotional, on women and girls who are not consenting to its practice. Emmanuel Ebah, a spiritual philosopher, talks from a broad canvas. He sets out the background and global prevalence with 2015 figures and covers legislation to end the practice. This is in the context of human rights agendas, including the right to life and non-violence, and the un-Christian and un-Islamic interpretation of inflicting pain and subjugating women.

The most effective sections of the book are the individual stories of women about their memories of being tricked into going to celebratory parties where they were held down and cut with dirty implements and the severe pain and immediate complications that followed. Mothers of these girls believed they were helping the daughters' acceptance in their societies and future prospects of marriage. There is juxtaposition of economic arguments for the family, who pay the circumcisers and may have no choice in letting complications go untreated due to cost, against loss of status if their daughters cannot marry; in some countries where there are publically funded healthcare systems there is a pressure to cope with shortand long-term sequelae.

The text quotes sources of data from World Health Organization, United Nations Population Fund and UNICEF, and in its 50 pages provides an overview that will be a helpful update to current knowledge. The author highlights in particular the recognition of the barbarity of the procedures, and how religious leaders, often against the local background political systems, have spoken out to educate people that there is no basis to the commonly held beliefs that FGM is proscribed in Islamic or Christian texts. Indeed it is believed that FGM predates both religions, with writings from ancient Greece and Rome telling of the practice. There appears to be some link to slaves having been infibulated to prevent them becoming pregnant, so raising their price.

Several regions, including some of the 29 African countries where FGM occurs, have had legislation in place for many years (in some instances decades) to end the practice, but as we are aware prosecutions are rare and there seems to be a degree of laxity depending on the type of FGM performed.

Ebah ends with recommendations to galvanise change. These include aligning laws with international conventions with increased identification and prosecution, education of local community leaders, increasing economic independence of women through training, and production of joint statements against the practice from religious leaders.

I feel that this book aids an overview by bringing together what is currently known about FGM at global level with hard-to-read personal accounts and suggestions for moving forward to end the practice.

Reviewed by Alyson Elliman

Locum Consultant, Sexual Health Services, Croydon Health Services NHS Trust, Surrey, UK

Competing interests None declared.

Provenance and peer review

Commissioned; internally peer reviewed.

Published Online First 10 May 2016

J Fam Plann Reprod Health Care 2016;42:212.

doi:10.1136/jprhc-2016-101520 